\title{
Establishment and refinement of segmental pattern in the Drosophila embryo: spatial control of engrailed expression by pair-rule genes
}

\author{
Stephen DiNardo and Patrick H. O'Farrell \\ Department of Biochemistry and Biophysics, University of California at San Francisco, San Francisco, California 94143 USA
}

\begin{abstract}
We are examining the development of the segmental body pattern of Drosophila by immunolocalization of engrailed, a developmental regulatory protein that maintains segmental subdivisions in the embryo, and is expressed in a spatially restricted (striped) manner that persists while the body pattern is being established and refined. A regulatory network among pair-rule segmentation genes establishes the striped pattern of engrailed expression. In general, mutations in particular pair-rule genes affect either even- or odd-numbered engrailed stripes. For example, fushi tarazu or odd-paired mutations delete even-numbered stripes, whereas paired mutations delete odd-numbered stripes. An analysis of engrailed expression in other mutants, including evenskipped odd-skipped double mutants, indicates that some pair-rule genes play a rule in establishing the correct width and position of engrailed stripes. Overall, the changes in engrailed pattern have consequences for final embryonic body pattern. Thus, the pair-rule loci, acting through engrailed, establish an early, general outline of body pattern. However, in several pair-rule mutants, engrailed patterns are dynamic, suggesting that as later events build upon this general rule to form the final body pattern, adjustments are made in response to the earlier pair-rule defect-that is, the pattern regulates.
\end{abstract}

[Key Words: engrailed expression; Drosophila; segmentation gene interactions; embryonic pattern; combinatorial control; cell interactions]

Received July 14, 1987; revised version accepted October 15, 1987.

The basic segemental body pattern of the fruit fly Drosophila melanogaster is established early in embryogenesis. After fertilization, a series of rapid nuclear division cycles converts the embryo into a shell of about 6000 nuclei at the periphery of a syncytial cytoplasm. The cellular blastoderm is formed by cellularization of each of these peripheral nuclei $[2.5 \mathrm{hr}$ after egg laying (AEL)]. By this stage the basic outlines of the segmental pattern have been established, as determined by cell marking and cell transplantation experiments (Wieschaus and Gehring 1976; Simcox and Sang 1983), although no morphological consequences of the pattern formation process are yet visible. We are interested in the molecular mechanisms that establish the early segmental body pattern and that build upon this early outline to establish the final form of the embryo.

Developmental regulatory genes that are thought to control the process of pattern formation have been identified (Nüsslein-Volhard and Wieschaus 1980; Jurgens et al. 1984; Nüsslein-Volhard et al. 1984; Wieschaus et al. 1984). Twenty or so zygotically expressed genes have been grouped into "segmentation gene" classes according to the positions and extent of cuticle pattern defects caused by mutations at these loci. The "gap" loci, such as Krüppel (Wieschaus et al. 1984b), are required for the establishment of relatively large contiguous do- mains (about seven segments). The pair-rule loci, such as fushi tarazu (Wakimoto et al. 1981), are required for the patterning of domains spaced roughly at two-segment intervals. A combined molecular and genetic analysis indicates that the gap and pair-rule loci function by the cellular blastoderm stage. Therefore, these genes are thought to be important in the establishment of early segmental body pattern (Nüsslein-Volhard and Wieschaus 1980; Hafen et al. 1984; Wieschaus et al. 1984b; Gergen et al. 1986).

A third class of segmentation gene-the "segment polarity" loci, such as wingless - is required for the development and polarity of domains within each segment. This class acts over a broad developmental period, beginning at the cellular blastoderm. These genes are probably involved in building upon the early segmental body pattern, establishing more detail in the pattern of cell fates. This period of embryogenesis covers the morphogenic movements of gastrulation $(3.5 \mathrm{hr} \mathrm{AEL})$, germband extension (3.5-5.5 hr AEL) and retraction (7-9 hr $\mathrm{AEL} \mid$, and two postblastoderm cell divisions. Although little is known of the mechanisms used to create more detail in pattern during these later stages, the suggestion that the wingless product may function in morphogenesis as a signal in cell communication is intriguing ( $\mathrm{Rij}^{-}$ sewik et al. 1987). 
Molecular probes for segmentation genes allow us to visualize the pattern formation process with single-cell precision, long before the morphological consequences are apparent. Perhaps the clearest manifestation of the early segmental pattern is the exquisite expression pattern of engrailed, a gene required for the maintenance of segmental pattern (Nüsslein-Volhard and Wieschaus 1980; Kornberg 1981a). In the adult, engrailed is required for the development of a portion of each segment (the posterior compartment; Garcia-Bellido 1975; Lawrence and Morata 1976; Kornberg 1981b). During embryonic development, the engrailed locus has attributes of both the pair-rule and segment polarity gene classes. [engrailed also has a role in precellular blastoderm development (Karr et al. 1986). It is unclear as yet whether this role is distinct from its role in segmentation.] The molecular analyses show that engrailed is expressed during embryogenesis in a position-specific manner such that 14 stripes are seen transecting the anteroposterior axis at intervals that correspond to the posterior portions of each developing segment (Fjose et al. 1985; Kornberg et al. 1985). Immunocytochemical localization of the engrailed protein in fixed whole-mount embryos shows that the antigen accumulates in stripes at the cellular blastoderm $(3 \mathrm{hr} \mathrm{AEL})$ and that this pattern persists for an extended period (DiNardo et al. 1985). It is this period during which patterns of cell fates are further specified. Therefore, by monitoring the engrailed pattern, we can follow both the establishment of the early segmental pattern outline and its refinement into a more detailed pattern (DiNardo et al. 1985).

To define the processes that are used during the establishment and refinement of pattern, we have determined the consequences that mutations in each of the pairrule genes have on the engrailed pattern. The early engrailed pattern shows that correct width and placement of each engrailed stripe requires the combined activity of several pair-rule genes. Even-numbered and oddnumbered stripes require distinct, but partly overlapping, subsets of pair-rule activities. When a given engrailed stripe is altered, so is the consequent development of posterior compartment structures in that region of the embryo. These results indicate that the pair-rule genes, acting through engrailed, are indeed primary regulatory loci that control early segmental patterning.

The results also reveal aspects of the process that build upon the early segmental pattern. In effect, each pair-rule mutation introduces a characteristic pattern defect at cellular blastoderm, as determined by alterations in the early engrailed pattern. During the course of continued development, we find that the system responds to this early pattern defect in ways suggesting that cell-cell interactions are important in the establishment of final cell fates.

\section{Results}

The control of early patterning events by pair-rule segmentation loci

The pattern of engrailed expression at cellular blasto- derm is altered in each pair-rule mutant. Although we have examined the strongest alleles available /unless specifically noted), in no case is engrailed expression abolished or globally induced throughout the embryo. Rather, particular stripes of expression seen in wild-type embryos are deleted, broadened, or repositioned, producing a distinct pattern in each mutant.

To describe the engrailed pattern, we number stripes in an anteroposterior sequence, $1-14$, and indicate their segmental fate parenthetically $(\mathrm{Mn}, \mathrm{Mx}, \mathrm{La} ; \mathrm{Tl}-\mathrm{T} 3$; Al-A8) (Figs. 1a; 2d). The segments are defined morphologically. Along the ventral surface of the larval cuticle, repeating groups of hairs, the denticle belts, mark thoracic $(\mathrm{T} 1, \mathrm{~T} 2, \mathrm{~T} 3)$ and abdominal $(\mathrm{A} 1-\mathrm{A} 8)$ segments. The oral segments, mandibular $(\mathrm{Mn})$, maxillar $(\mathrm{Mx})$, and labial (La), largely involute and do not contribute to the external markers considered here. In Figure 1, the stippled area within each segment approximates the region where engrailed gene activity is required earlier in development (Nüsslein-Volhard and Wieschaus 1980; Kornberg 1981a). These engrailed-requiring regions cover some naked cuticle in each segment and the most anterior row of denticles in A2-A8 (Gergen et al. 1986; S. DiNardo and P. O'Farrell, unpubl.). By convention we refer to segments, their primordia, and component pattern elements (e.g., denticle belts) as odd numbered (T2, $\mathrm{A} 1, \mathrm{~A} 3, \mathrm{~A} 5$, and $\mathrm{A} 7)$ or even numbered (T1, T3, A2, A4, $\mathrm{A} 6$, and $\mathrm{A} 81$.

Expression of odd-and even-numbered engrailed stripes is controlled by different combinations of pairrule genes Whether a pair-rule mutation deletes, broadens, or repositions engrailed stripes, each mutation has distinct effects on even- versus odd-numbered stripes (Fig. 6). Furthermore, these genes act in combinations. For example, the combined activity of six pairrule genes is required for the production of even-numbered stripes of correct width and position (ftz, opa, eve, runt, hairy, and odd). In this section we focus on mutations that cause the deletion of specific stripes; fushi tarazu (ftz) and odd-paired (opa) mutants lack evennumbered stripes, whereas paired (prd) and unpaired (upd) mutants lack odd-numbered stripes.

Figure 2 shows the pattern of engrailed expression in wild-type, $f t z$, and prd mutant embryos at two stages of development $[3.5 \mathrm{hr}$ AEL (a, b, and c) and $\sim 7 \mathrm{hr}$ AEL (d, $\mathrm{e}$, and f)|. In the mutants only 7 , rather than 14 , engrailed stripes are formed. The intensity of the developing stripes and their position indicate that $f t z$ mutants lack even-numbered stripes (Figs. $1 \mathrm{~b}$ and $2 \mathrm{~b}, \mathrm{e}$ ), whereas prd mutants lack odd-numbered stripes (Figs. 1c and $2 \mathrm{c}, \mathrm{f})$. As in wild type, the engrailed stripes that form in $f t z$ and $p r d$ mutants are one single cell wide. However, these stripes are now separated by six to eight cells rather than two or three cells. If engrailed expression reflects the specification of cell fates, a compound segment having an enlarged anterior compartment and a normal posterior compartment would be anticipated. Indeed, the effects on engrailed expression antic:pate the morphological defects. First, cuticular pattern elements 


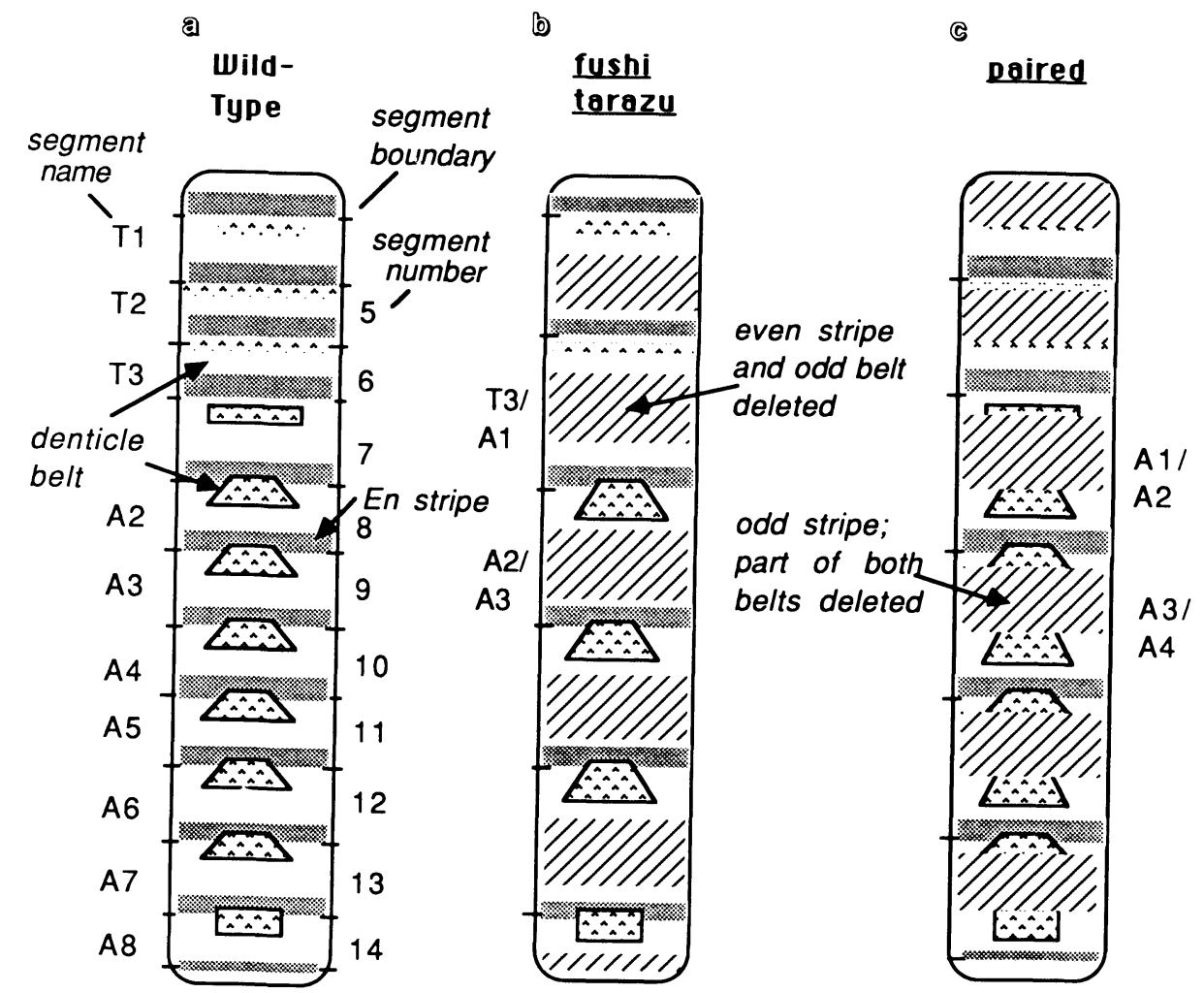

Figure 1. A schematic representation of the wild-type, $f t z$, and prd larval cuticle with the pattern of engrailed expression superimposed. (a) Selected ventral characteristics of a wild-type embryo at hatching. The thoracic (T1-T3) and eight abdominal (Al-A8) segments are externally visible; cuticular derivatives of the oral ( $\mathrm{Mn}, \mathrm{Mx}, \mathrm{La})$ segments, which have largely involuted, and the complex terminalia have been left out for clarity. The approximate positions of segment boundaries are marked $(-)$. Note that this boundary actually lies just within the denticle belt of segments A2-A8 (Szabad et al. 1979). The T1-T3 and Al denticle belts probably do not overlap this boundary. The posterior portion of each segment is comprised of mostly naked cuticle. The placement of the engrailed stripes is approximate. These overlap mostly naked cuticle and the anterior row of denticle hairs in A2-A8. This placement is derived from a consideration of the pattern elements lost in a weak engrailed mutant, en ${ }^{I M 99}$ at $18^{\circ} \mathrm{C} / \mathrm{Gergen}$ et al. 1986 ; S. DiNardo, unpubl.). (b) Pattern elements deleted in a ftz embryo. The regions deleted, indicated by crosshatching, extend from the middle of the naked cuticle in even-numbered segments through the next denticle belt, ending in the naked cuticle region of the adjacent odd-numbered segment, resulting in compound segments, e.g., T3/A1, A2/A3, etc. The remaining denticle belts are broadened relative to wild type. The frame of deletion should effect even-numbered engrailed stripes (see Fig. 2). (c) Pattern elements deleted in a prd embryo. The deletions are in a different frame from those in $f t z$ embryos. The deletion takes out part of the denticle from belt and the naked cuticle of odd-numbered segments and part of the adjoining even-numbered denticle belt, resulting in compound segments, e.g., A1/A2, A3/A4. The composite denticle belts are broadened relative to wild type. The deletion frame should affect odd-numbered engrailed stripes (see Fig. 2).

that would derive from even-numbered engrailed stripes are absent in $f t z$ mutants [e.g., 6(T3) in Fig. 1b]; whereas those that would derive from odd-numbered stripes are absent in prd mutants [e.g., 9(A3) in Fig. 1]. Some of this pattern deletion may be the result of cell death at later stages. Second, the mutants develop fused (compound) segments, having disproportionately wide denticle belts characterized by duplicated rows of denticles /reflecting an enlarged anterior compartment; Nüsslein-Volhard et al. 1985). Thus, beyond any cell death that might occur, some misspecification of cells occurs and appears to contribute to the final pattern.

The $f t z$ and $p r d$ gene products do not act alone in the establishment of even- and odd-numbered engrailed stripes. Like $f t z$ mutants, early opa embryos also lack even-numbered stripes (Fig. 3a), although after germ- band extension, there is some engrailed expression roughly corresponding to the location of even-numbered stripes (Fig. 3b). This expression is usually faint and clustered near the ventral midline. Interestingly, at these later stages the expression in odd-numbered stripes is sometimes irregular [5(T2), bold arrow, Fig. 3b]. Such late changes in engrailed pattern occur in many pair-rule mutants. We will describe in detail the late changes observed in one particular pair-rule mutant, odd-skipped, in a later section, and we will consider the implications of such late changes in the Discussion.

Like prd mutants, seven odd-numbered stripes are missing in upd mutant embryos (Fig. 3c). However, this phenotype is not fully penetrant. Twenty-five percent of the mutant embryos show this drastic and early effect on engrailed pattern. In the remaining mutant embryos, 
a

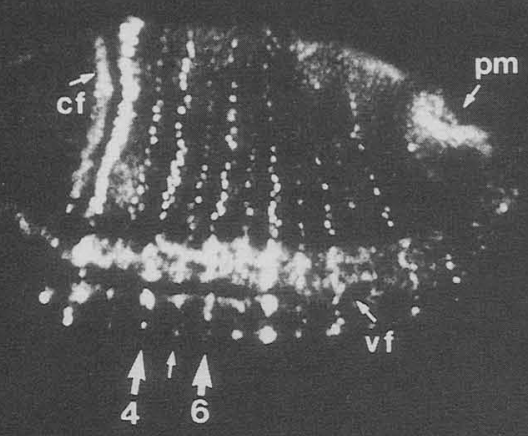

b

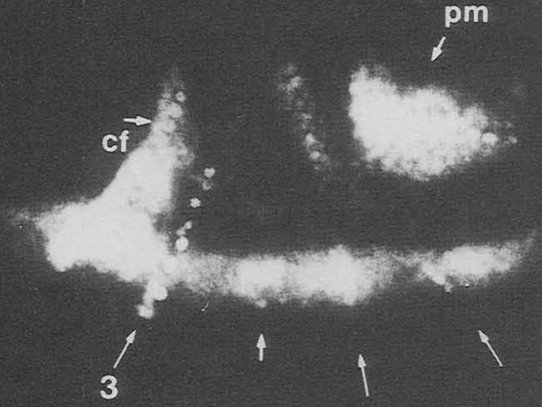

C

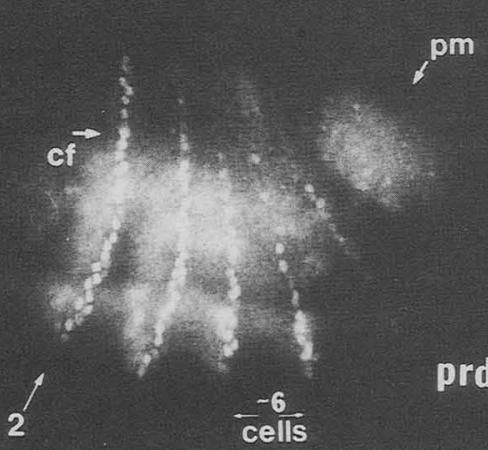

d

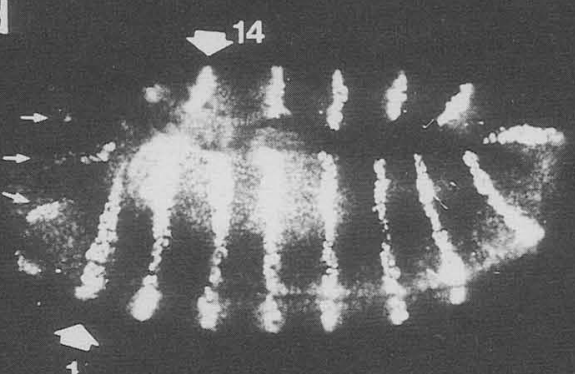

$\Leftrightarrow$

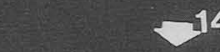

14
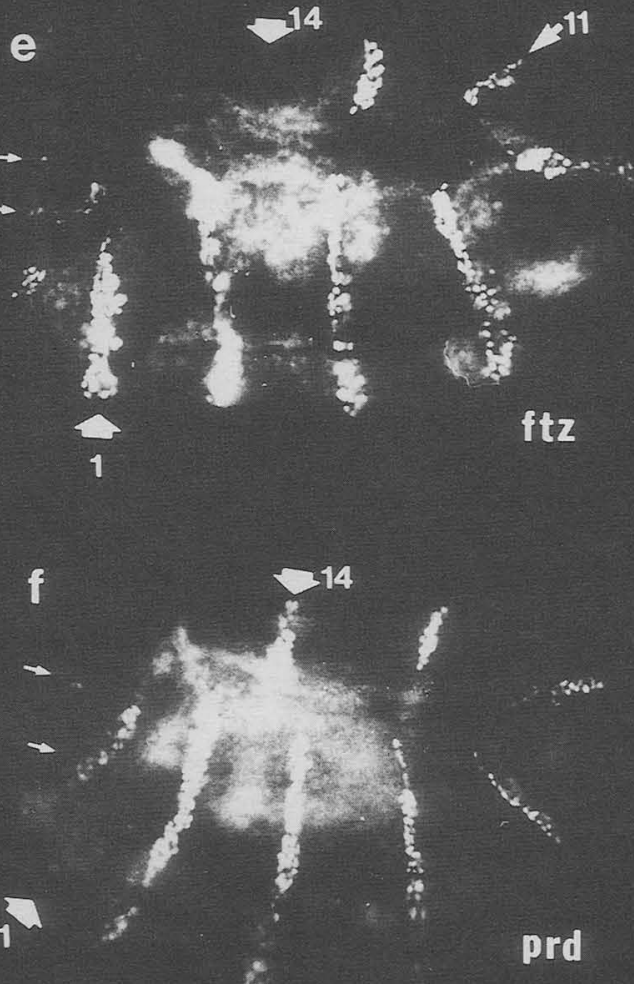

Figure 2. $f t z$ is necessary for even-numbered stripes, and prd is necessary for odd-numbered stripes. Embryos are oriented anterior left and ventral down (roughly) in all images, unless otherwise noted. (a) Wild-type, early gastrula. The stripes are roughly one cell (nucleus) wide, with alternating (even-numbered) stripes higher in signal intensity. The stripes are about 2.5 cells aparts (S. DiNardo, unpubl.). (b) $f t z^{W 20}$ mutant, beginning germ-band elongation. Fewer stripes are visible, and those that are present are particularly light. These are odd-numbered stripes, which may take longer to appear than in wild-type (cf. $a$ ). The $1(\mathrm{Mn})$ stripe is within the cephalic furrow (cf) and not in this focal plane. The 3(La) stripe and other stripes more easily visible in the original preparations [7|A1), 9(A3), and 13(A7); larger arrows] mark a four-segment periodicity. The stripes are one cell wide. This is seen clearly for $3(\mathrm{La})$. $f t z^{\mathrm{E} 66-1}$ exhibits the same pattern as $f t z^{W 2 O}$ at all stages. ( $c$ prd $_{2.45}$ mutant, early gastrula. Five even-numbered stripes are visible here, with a hint of the sixth (the seventh will become apparent as development progresses). These are one cell wide, as in wild type, and there are about six to seven cells between stripes. (d) Wild-type embryo at $\sim 7 \mathrm{hr}$ AEL. Fourteen stripes representing the posterior compartment primordia of the oral, thoracic, and eight abdominal segments are indicated. Small arrows point out other pockets of engrailed expression, but these are not of primary concern here. The $1(\mathrm{Mn})$ and the $14(\mathrm{~A} 8)$ stripes (broad arrows) are good reference points in comparisons between this and the mutant embryos in panel $e$ and $f$. $(e) f t z^{\text {W20 }}$ mutant at $7 \mathrm{hr}$ AEL. Seven odd-numbered stripes are present. Stripe 11 (A5) is sometimes missing. In agreement with this, we find that a fraction of $f t z$ embryos have a compound fusion of A4 with A6. Small arrows point to preoral pockets of engrailed expression, which are identical to wild type $(d)$. $(f) \operatorname{prd}^{2.45}$ mutant at $7 \mathrm{hr}$ AEL. There are seven even-numbered stripes, starting at $2(\mathrm{Mx})$, and some preoral expression (small arrows). Segment primordia and engrailed stripe designations are described in the legend to Fig. 1 and the text. (vf) Ventral furrow; (cf) cephalic furrow; (pm) posterior midgut invagination. 
early engrailed expression appears normal, but defects develop after the germ band is fully extended. In these cases, stripe 10/4) is partially or totally deleted (Fig. 3d). When visible, the remnant of the $10 \mathrm{~A} / 4)$ stripe is shifted posteriorly (Fig. 3d). These late alterations in engrailed pattern are compatible with the most frequent cuticular defect, which is a deletion of the A5 denticle belt and the posterior portion of A4/Gergen and Wieschaus
1986). These investigators also describe a more severe and complex cuticular phenotype in a fraction of upd mutant embryos. This class of embryos probably derives from the mutants that show a severe and early effect on engrailed pattern. It is not clear why such disparate phenotypes arise.

We conclude that even- and odd-numbered engrailed stripes are controlled by distinct genes: $f t z$ and opa ac- a

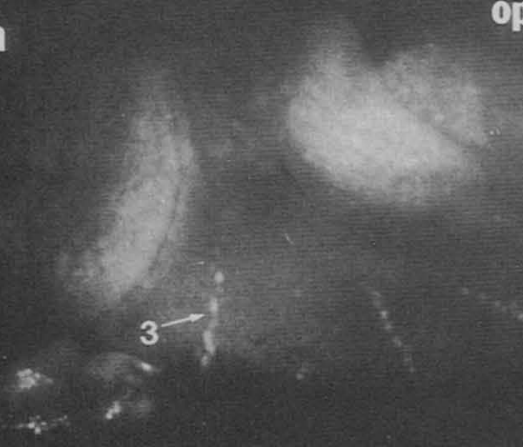

Opa
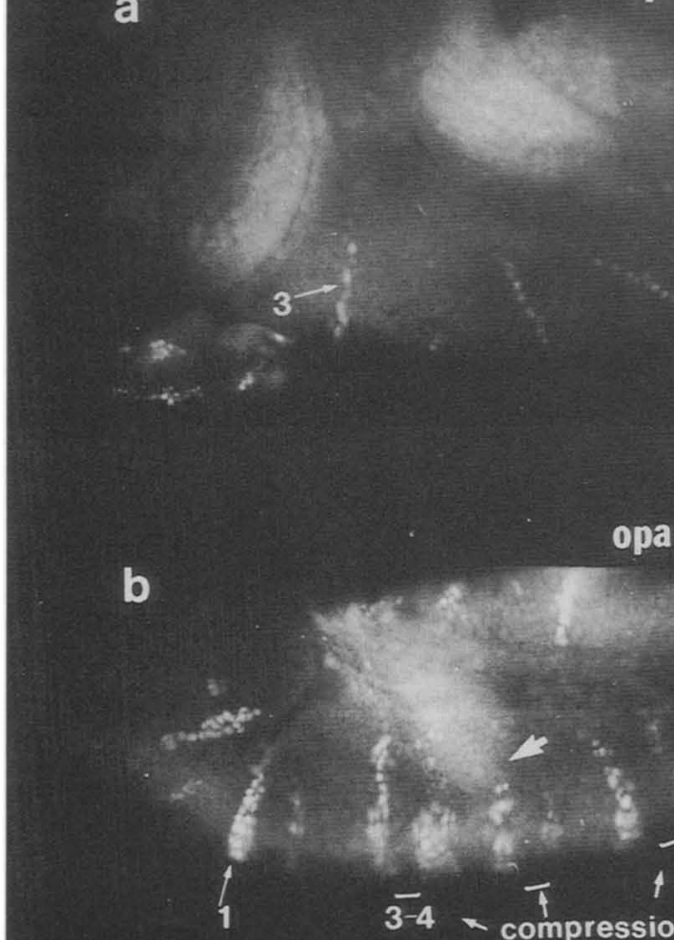

opa

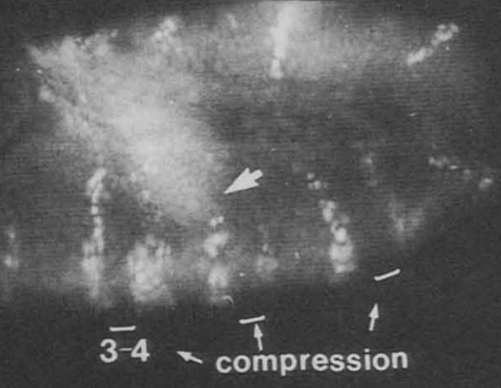

C

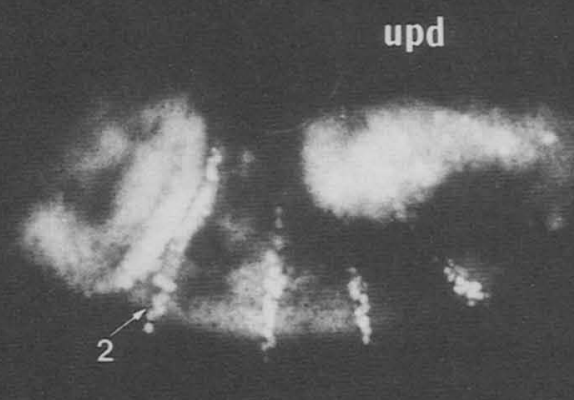

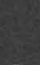

d

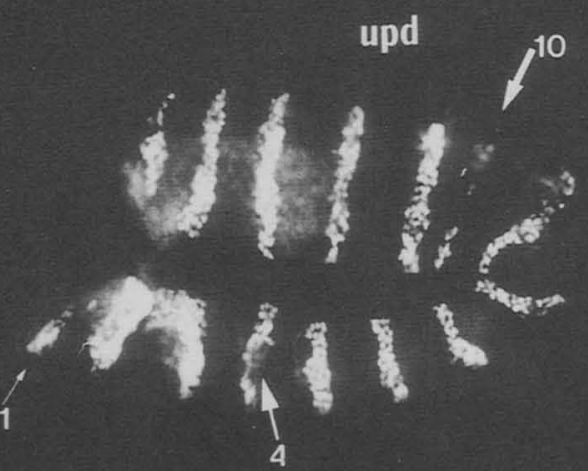

Figure 3. opa and upd are also required for even-numbered and odd-numbered stripes, respectively. (a) Early opa ${ }^{I I C 41}$, beginning germ band extension. engrailed antigen accumulation is similar to that in $f t z$ embryos, with only odd-numbered stripes developing. The $3(\mathrm{La})$ stripe is most evident. The $1(\mathrm{Mn})$ stripe is within the cephalic furrow (cf). There is a hint of one even-numbered stripe, 12(A6), at this early stage (arrowhead). The developing stripes are one cell wide. opall32 exhibits a similar pattern. $(b)$ opa ${ }^{l l C 41}$ embryo at 7 hr AEL. The seven odd-numbered stripes are most evident beginning with $1(\mathrm{Mn})$; however, there is expression to varying degrees between odd-numbered stripes. The expression here could be even-numbered stripes, but they are displaced anteriorly (brackets reflect this compression). The cuticular pattern deletions in opa embryos are centered within the denticle bands of even-numbered segments. The compression of segment primordia between engrailed stripes at the expense of anterior (denticle) portions of even-numbered segments anticipates these cuticle defects. The even-numbered stripes are not complete in the dorsoventral direction. Some odd-numbered

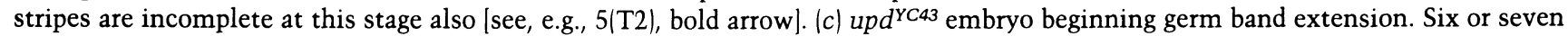
stripes are developing. Analysis of later embryos with similar staining patterns (not shown) indicates that these are probably evennumbered stripes, as in prd mutants. Only one quarter of mutant embryos show this early and clearly pair-rule effect on the engrailed pattern. The rest are normal at this stage. (d) Late upd ${ }^{Y C 43}$ embryo $(\sim 6 \mathrm{hr}$ AEL), showing the most penetrant effect on engrailed pattern. Defects are apparent in the 10(A4) stripe (arrow) and frequently in the 12(A6) (not seen in this embryo) and 4(T1) stripes. These defects develop over time. They are not apparent in early embryos. 
tivity are required for even-numbered stripes, and prd and upd (to a variable extent) are required for odd-numbered stripes. In addition, we show below that other pair-rule genes are required for the appropriate placement and width of either even- or odd-numbered stripes (see Fig. 6).

Regulatory interactions among genes that control engrailed expression and cell fate Although it is possible that some pair-rule gene products directly regulate engrailed expression, the existence of regulatory interactions among particular pair-rule genes (Carroll and Scott 1986; Harding et al. 1986; Howard and Ingham 1986) makes the assignment of a direct regulatory role to these genes problematic. Our analysis of a loss-of-function mutation of even-skipped (an eve null allele) illustrates the consequences that such regulatory interactions have for engrailed expression.

The eve null mutation leads to the absence of 14 engrailed stripes (Fig. 4a; Harding et al. 1986; MacDonald et al. 1986) and produces an unsegmented embryo (Nüsslein-Volhard et al. 1985). These results would appear to indicate an essential role for eve in establishing engrailed expression in stripes and for segmentation. However, Gergen et al. (1986) showed that the double mutant combination of eve and odd has appreciable segmentation (but not resembling wild type). Figure $4 \mathrm{~b}$ shows that a striped pattern of engrailed expression returns in this double mutant. Thus, striped engrailed expression per se does not require eve function, nor does (partial) segmentation of the embryo. Rather, eve function is coupled to the activity of the odd locus; and therefore, we cannot determine whether either gene has a direct or indirect role in regulating engrailed. However, although striped engrailed expression is produced in the eve odd double mutants, the pattern is neither wild type nor is it similar to the pattern observed in odd single mutants (described below). In the double mutant, even-numbered stripes are two cells wide (Fig. $4 \mathrm{~b}$ ), and odd-numbered stripes are present in only $50 \%$ of mutant embryos. Therefore, it would be inappropriate to conclude that eve and odd are dispensable with respect to engrailed expression. Rather, the observations here and below show that the full complement of pair-rule gene activities, along with their attendant interactions, is required for the proper spatial programming of this striped expression.

Pair-rule mutations can produce spatially complex engrailed patterns The simple deletion of alternate engrailed stripes is unique to $f t z$ and $p r d$ mutations. In other pair-rule mutants the width, spacing, or integrity of the stripes is affected upon their establishment (Fig. 6), and these characteristics change progressively during development. Such changes are found in embryos having strong or null mutations in genes such as hairy, runt, and odd-skipped. Rather than describe each case in detail, we describe the effects of a particular mutation selected because it illustrates all of these types of changes.
This allele $e v e^{3.77}$, is not null for function (Nüsslein-Volhard et al. 1985). The spatial changes are considered here, whereas the temporal changes are reserved for the next section where the primary focus will be temporal aspects of patterning.

Although all engrailed stripes are missing in eve null mutants (above), the $e v e^{3.77}$ mutant shows complex alterations in the pattern of engrailed expression. First, the relative spacing between engrailed stripes is altered, for example, brackets point out the apposition of the 5(T2) and 6(73) stripes in Figure 4c and d. This spacing change is observed for each odd/even pair of stripes. Because engrailed marks the prospective posterior compartment of segmental primordia, the reduced spacing between certain pairs of engrailed stripes in $e v e^{3.77}$ indicates that the anterior compartment primordia are smaller. This could account, at least in part, for the ultimate cuticular pattern deletions, which are centered in the anterior region (denticle belt) of each even-numbered segment.

The repositioning of a stripe is a complex change in regulation. A row of cells that would normally express engrailed no longer does so in the mutant, but rather an adjacent row expresses. To effect such a change in pattern, the distribution of several developmental regulatory proteins, such as other pair-rule gene products (see Discussion; Harding et al. 1986), is probably altered by this allele. It is possible that other pair-rule mutations that affect the positioning of en stripes (e.g., runt, Fig. 6) do so by affecting the expression of several pair-rule genes.

Second, although all odd-numbered stripes are affected, the particular effect of this eve allele varies, depending on the particular odd-numbered engrailed stripe considered. Stripes 7(A1), 9(A3), and 11(A5) are incomplete ventrally, stripe $3(\mathrm{La})$ is incomplete laterally, and stripe $1(\mathrm{Mn})$ is absent (Fig. 4d). Stripe 5(T2), the only odd stripe intact along its dorsoventral axis, shows a singular alteration, being broader than normal (Fig. 4d), although this increase in breadth develops over time (see below). Thus, although $e v e^{3.77}$ has a pair-rule effect on engrailed-each odd engrailed stripe is altered-the nature of the alteration in each stripe varies. The en pattern in runt and hairy mutants is not altered in a precisely periodic fashion, with particular stripes being wider than others or spaced more closely to others (Fig. 6). Such observations suggest that the requirement for the activity of particular pair-rule genes varies along the anteroposterior axis.

The dynamic nature of the engrailed pattern in pairrule mutants reveals progressive aspects of the pattern formation process

Late changes are evident in the engrailed pattern observed in the eve hypomorph already discussed. For example, there is a striking increase in the width of stripe 5(T2) (cf. Fig. 4c and d). In addition, odd stripes such as 
7(A1) and 9(A3) are faint in the early gastrula, only becoming prominent later. We also observe complex temporal alterations in engrailed pattern in hairy, runt, and sloppy-paired mutant embryos, but we will reserve their full description for elsewhere (for hairy, see also Howard and Ingham 1986). We have already alluded to late changes that occur in opa and in some upd mutants. We note only that, as in the case of the eve hypomorph, each of these mutations causes early and reproducible engrailed pattern defects (Fig. 6) and that in each case these early defects are further altered during the course of development. Some insight into the process(es) that are driving these further patterning changes comes from an analysis of the dynamic nature of the engrailed pattern in odd-skipped embryos.

Early in the development of odd mutants, even-num-

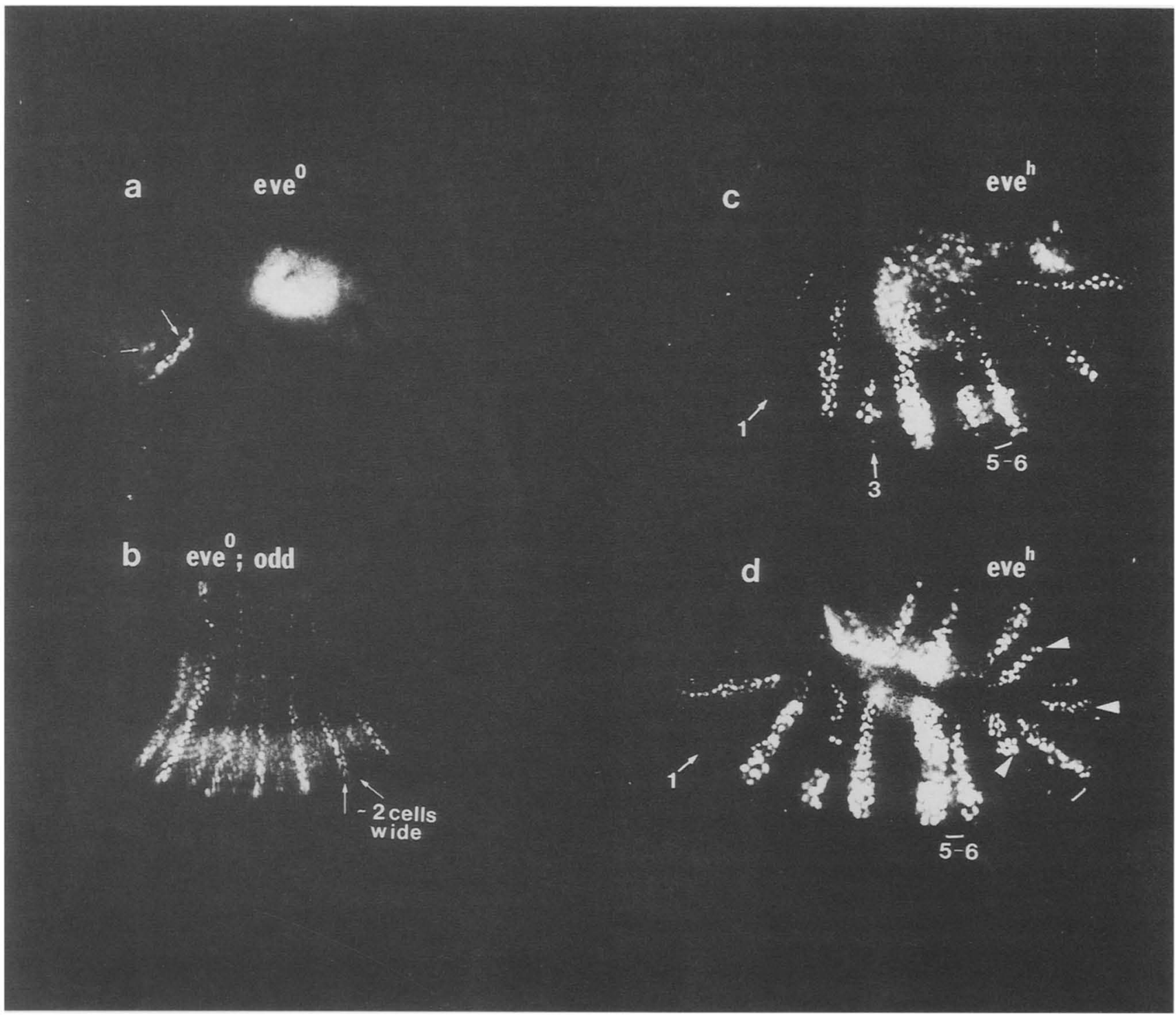

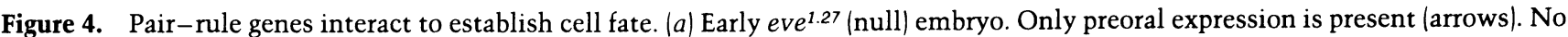
striped expression is apparent along the oral, thoracic, and abdominal region. eve $e^{0}$ indicates a null allele. $(b) e v e^{1.27}$ (null), odd $d^{1 I I D 36}$ double mutant, early gastrula. A striped pattern of engrailed expression is restored. The pattern is not wild type, with particular stripes being two cells wide instead of one. The effect of this double-mutant combination on the engrailed pattern will be analyzed in detail elsewhere. (c) eve $e^{3.77}$ (hypomorph), beginning germ band extension. There are several alterations in the engrailed pattern. Odd-numbered stripes are defective. For example, the $1(\mathrm{Mn})$ stripe is not present; the $3(\mathrm{La})$ stripe is confined to a few ventral cells. Second, odd-numbered stripes are shifted, appearing closer to the next most posterior stripe. The 5(T2)-6(T3) pair is bracketed to show this shift. The $4(\mathrm{~T} 1)$ stripe is broader than usual. eve $e^{h}$ indicates a hypomorphic allele. (d) eve $e^{3.77}$ (hypomorph) at $6 \mathrm{hr}$ AEL. The shifted position of odd-numbered stripes at the expense of anterior portions of the next, even-numbered segment is indicated for the pairs $5(\mathrm{~T} 2)-6(\mathrm{~T} 3)$ and $7(\mathrm{~A} 1)-8(\mathrm{~A} 2)$ and is true for other pairs as well. The $5(\mathrm{~T} 2)$ stripe has broadened dramatically relative to other stripes, [cf. 5(T2) in c]. Several stripes are present dorsolaterally [7(A1), 9|A3), and 11(A5) arrowheads], with only a minority of the ventral cells expressing (not in this plane of focus). 
bered engrailed stripes are two cells wide instead of one, whereas the odd-numbered stripes are normal (Fig. 5a). The distance between the broadened even stripes and the next most posterior stripe is two cells rather than the normal three (Fig. 6). Thus, the expansion of the even-numbered stripe is at the expense of the primordia for anterior parts (denticle belts) of odd-numbered segments.

After the germ band is fully elongated ( $\sim 6 \mathrm{hr}$ AEL), the aberrant engrailed pattern changes. Each broad engrailed stripe splits almost completely into two stripes. The embryos in Figure 5 (b,c,d) show this progression. It appears that cells toward the middle of the broad stripe lose engrailed signal. The position and extent of this split is variable both in different odd embryos and in comparing stripes within the same embryo (Fig. 5d). Cells that have lost signal are grouped and not intermingled among expressing cells.

The initial engrailed pattern and the later transition can be correlated with the cuticular phenotype of odd mutant embryos (first described by D. Coulter and E. Wieschaus, pers. comm.). The region of cuticle deleted is shown schematically in Figure $5 \mathrm{e}$. The odd-numbered denticle belts are almost completely missing. In place of these, there is a mirror-image duplication of the derivatives of even-numbered engrailed stripes (Fig. 5f). Up to this point in the description, part of the pattern deletion and duplication can be accounted for by the misspecification of cell fate at blastoderm as seen by changes in the early engrailed pattern. The even-numbered engrailed domains have been "duplicated" and this duplication is at the expense of a row of cells normally specified with anterior (denticle) cell fates. Therefore, the outlines of the final cuticular pattern are established early in odd mutants. This holds for mutations at other pair-rule loci also and confirms the suggestion that pair-rule genes are among the primary loci to consider in contemplating the establishment of segmental pattern (Gergen et al. 1986). However, a close look at the denticle remnant in odd mutants suggests that not all pattern elements within the duplication are accounted for by derivatives of engrailed-expressing cells (Fig. 5f) and, therefore, that some further alteration of this early "framework" of pattern must occur. This further alteration seems to be reflected in the splitting of the broad engrailed stripes.

The denticle remnant is composed of an anterior row of small denticles, each pointing anteriorly and resembling those normally secreted by engrailed-expressing cells. Behind this row are one or two rows of large denticles ordinarily produced by non-engrailed-expressing cells (cells in the anterior region of a segment). The polarity of denticles in these two rows is somewhat variable, possibly reflecting the fact that the plane of mirrorimage symmetry lies here. At the posterior edge of this remnant is another row of small denticles of the type normally secreted by engrailed-expressing cells but with opposite polarity (pointing posteriorly). It is the "intercalated" anterior pattern elements that are not accounted for by the blastoderm engrailed pattern. It is possible that some of the cells that lose engrailed signal within the broad stripes give rise to the intercalated row of large denticle hairs, that is, the final fate of these cells is being respecified. If so, these transitions in engrailed staining reflect a process that intercalates new cell fates during the postblastoderm stage of pattern refinement (see Discussion).

\section{Discussion}

The results reveal two aspects of the pattern formation process during Drosophila embryogenesis. The first concerns the establishment of early segmental pattern through the regulatory activities of the pair-rule segmentation genes. We show that the precise spatial pattern of engrailed expression, which is a marker for the establishment of segmental pattern, depends upon combinatorial interactions among these segmentation genes. The correct width and spacing of even- and odd-numbered stripes requires two distinct subsets of pair-rule gene activity. Importantly, if the engrailed pattern at cellular blastoderm is altered in a pair-rule mutant, say, by a broadening or repositioning of particular engrailed stripes, then so is the consequent development of posterior compartment pattern elements in the corresponding region of the embryo. This demonstrates that pair-rule gene activity is a primary determinant in establishing an outline for the final body pattern and, furthermore, that this role is mediated, in part, through the spatial regulation of engrailed.

The second aspect of our analysis is that the final body pattern is not necessarily a simple projection forward from the pattern at blastoderm. We find changes in the pattern of engrailed expression over time in several of the pair-rule mutants. This appears to be the result of embryonic pattern regulation, visualized at the level of gene expression.

\section{Establishment of blastoderm pattern}

Pattern formation relies on the expression of developmental regulatory genes in precise spatially restricted domains Developmental regulatory gene products are expressed in very precise patterns in the early embryo (e.g., Hafen et al. 1984; Harding et al. 1986; Kilcherr et al. 1986; MacDonald et al. 1986; for a review, see Scott and O'Farrell 1986). There is a correlation between the expression pattern for a given gene and the placement of pattern defects due to mutations in that gene. Such a correlation has suggested that ectopic expression of these genes would redirect the fates of expressing cells. Evidence supporting this is accumulating. For example, presumed unregulated (Gergen and Wieschaus 1986a) or global (Struhl 1985) expression of particular pair-rule genes causes pattern defects. Indeed, we find that alterations in engrailed gene expression that are induced by pair-rule mutations are associated with corresponding alterations in cell fate. Perhaps most instructive, the duplication of even-numbered engrailed stripes seen in odd-skipped mutants gives rise to correspondingly du- 
plicated posterior compartment structures and segment borders. A similar correlation between ectopic en expression and changes in body pattern is observed in the segment polarity mutant patched (in prep.). In these cases, inappropriate engrailed expression correlates with the production of new posterior pattern elements. Therefore, the establishment of precise, spatial patterns of segmentation gene expression is a crucial step in the development of embryonic pattern.

\section{Combinatorial signals determine patterns of cell fate}

A knowledge of the effects of pair-rule mutations on engrailed pattern cannot define in mechanistic detail the complex interactions involved in the establishment of engrailed expression and, therefore, patterns of cell fate at blastoderm. However, the overall features that govern these processes are revealed (see also, Howard and Ingham 1986). First, the pair-rule gene products required for odd-numbered stripes differ in part from those required for even-numbered stripes (Fig. 6). For example, $f t z$ and opa activity are necessary for the establishment of expression in even-numbered stripes but not oddnumbered stripes. Reciprocally, prd activity is required only for the odd-numbered stripes. Thus, engrailed responds to two distinct sets of regulatory factors, which in turn suggests that there may be distinct cis-acting control regions, one each for even- and odd-numbered en stripes. In addition, we expect that some of the pair-rule gene products are direct trans-acting regulators of the engrailed gene. Three of the four pair-rule gene products characterized to date contain homeo domains
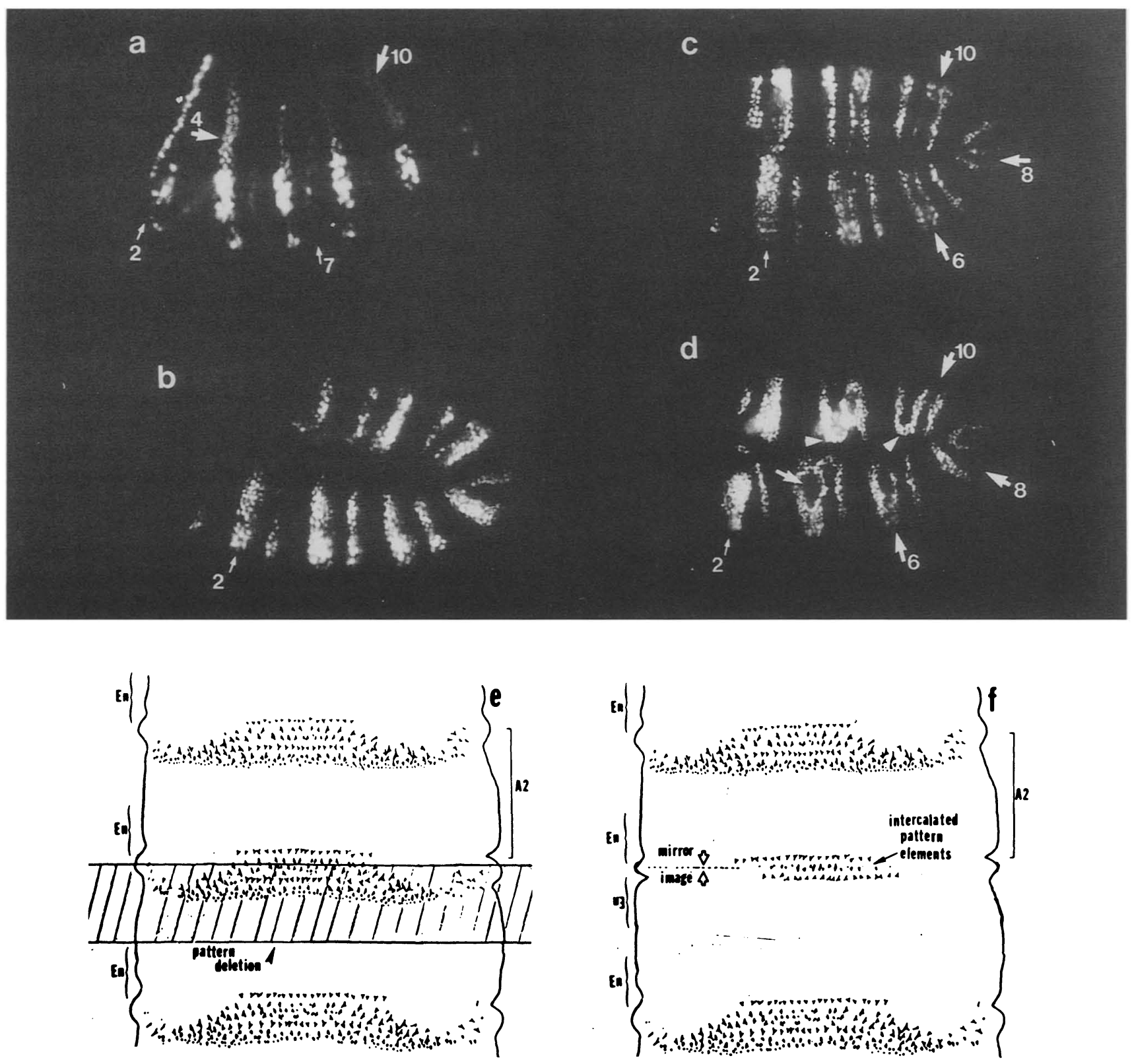

Figure 5. (See facing page for legend.) 
[ftz, prd, and eve (Laughon and Scott 1984; Frigerio et al. 1986; MacDonald et al. 1986; Frasch et al. 1987)l. Furthermore, this domain has sequence-specific DNAbinding activity (Desplan et al. 1985) and binds to several sites in the engrailed upstream regulatory region. The results reported here cannot distinguish between the role of an activator or a repressor of engrailed expression.

A second overall feature revealed by these analyses is that although a particular pair-rule product is necessary for expression in even-numbered stripes, it is not sufficient. As shown schematically in Figure 7, pair-rule products are distributed in relatively broad stripes at the onset of gastrulation. If, for example, the presence of $f t z$ were sufficient for engrailed induction, the engrailed stripes would be three cells wide rather than one cell wide. Because $f t z$ is not sufficient to specify engrailed expression, engrailed must respond to a combination of input signals (perhaps other pair-rule products). And, in fact, there must be two "combinatorial codes," one for even- and one for odd-numbered stripes. Combinatorial control could imply that several gene products act together to affect engrailed or, alternatively, imply an indirect pathway where one gene product affects the expression or activity of another, which in turn affects engrailed.

Such combinatorial control of cell fate reflects the refinement of a relatively coarse pattern (broad pair-rule stripes) into a more detailed pattern (single-cell-wide segmental stripes). Stripes of expression for different pair-rule genes are offset from one another by increments of one or two cell diameters (Fig. 7 and references therein). Such overlap gives rise to particular combinations of regulatory products in each row of cells. This would be sufficient to distinguish the fate of one row from the next (also see Gergen et al. 1986). One outcome of this is the production of stripes of engrailed expres- sion that are one cell wide. Therefore, by responding to a specific combinatorial code, engrailed marks one row of cells out of every three or four as distinct. We would predict that other segmentation genes (some of those among the segment polarity class) would respond to a different combinatorial code and, therefore, mark each of the remaining rows of cells in the segment primordium. In this manner, the combinatorial control of gene expression by developmental regulatory products has refined patterning domains from three or four cell widths (the domain of any one pair-rule product) to a single cell width.

\section{Regulatory interactions connect the segmentation genes in a network}

Recent work has shown that pair-rule genes themselves interact in the establishment of positional identity. For example, the $f t z$ pattern of expression is dependent on eve, hairy, and runt (Carroll and Scott 1986; Howard and Ingham 1986). eve, odd, and runt mutations have consequences on the engrailed pattern that appear to involve such interactions.

First, even though the 14 engrailed stripes are absent in an eve null, striped expression returns in eve, odd double mutants. The molecular nature of this interaction between eve and odd is not clear. Because stripes of eve expression overlap odd-numbered en stripes, eve could play a direct role in establishing these en stripes (Lawrence et al. 1987), although we would argue that eve would not be sufficient in this role for the same reasons argued above for $f t z$. In contrast, eve stripes do not overlap developing even-numbered en stripes, suggesting that eve may only affect these stripes indirectly. In particular, eve may affect these stripes through some regulatory consequences on the odd gene. This possibility arises because in an odd mutant, even-numbered

Figure 5. The late changes in engrailed pattern in odd mutants may reflect the intercalation of new cell identities. $(a)$ odd ${ }^{I I D 36}$ early gastrula. The even-numbered stripes are two cells wide, rather than one [see stripes 4(T1) and 10(A4)]. The position of one developing odd-numbered stripe is indicated [7(A1)]. The spacing between the odd-numbered stripes and each previous broad stripe is less than that in wild type, indicating that the expansion of even-numbered engrailed primordia is at the expense of the anterior domain of odd-numbered segments. The low intensity of the odd-numbered stripes is probably normal as this is also a feature of odd-numbered stripes in early wild-type embryos (Fig. 2a). The strength of the ventral-most signal is an optical effect due to the contribution of expressing cells in the invaginated mesoderm. $(b)$ Embryo at $5 \mathrm{hr}$ AEL. The pattern described in $a$ is quite apparent. Note the broad even-numbered engrailed stripes and the reduced primordia of the next most posterior (odd) segment. This broadening is at the expense of anterior (denticle) regions. (c) Embryo at $6.5 \mathrm{hr} \mathrm{AEL}$. The pattern is beginning to change. Cells within most broad stripes seem to be losing signal [6(T3), 8(A2), 10(A4) shown by arrows]. (d) Embryo at $\sim 7-7.5 \mathrm{hr}$ AEL. The broad stripes have split almost completely in two. The same three primordia are shown by arrows, as in $c$. In cases where stripes have not completely split, contiguous groups of cells have changed [arrow, $4(T 1)]$. In some cases, odd-numbered stripes and part of the split even-numbered stripes have reorganized dorsally so that they are joined $[10(\mathrm{~A} 4)-11(\mathrm{~A} 5)$ and $12(\mathrm{~A} 6)-13(\mathrm{~A} 7)$, arrowheads]. (e,f) Schematic representation of the pattern changes in A2 and A3 and part of A4 ventral cuticle in odd embryos. The regions of naked cuticle and anterior-row denticle hairs that require engrailed function are indicated by brackets in the left margin. $(e)$ The region deleted in odd embryos includes most of the A3 denticle belt, as indicated by hatching. The regions requiring engrailed function are not within the domain deleted in odd mutants. Therefore, we expect and observe the correct number of engrailed stripes in the early embryo. $(f)$ In odd embryos the deleted region is replaced by a duplication of naked cuticle and anterior-row denticle hairs. The orientation of denticle hairs indicates that the duplication has a reversed polarity. The resulting mirror image is indicated by head-to-head arrows. The duplicated pattern elements that require engrailed function are indicated by brackets in the margin. The blastoderm engrailed pattern anticipates both this pattern duplication and at least part of the loss of anterior (denticle) region in odd-numbered segments. Recall that single-cell-wide, evennumbered engrailed stripes have been "duplicated" and are thus two cells wide in early odd embryos $(a)$. Intercalated, large denticle hairs are pointed out, nestled between the anterior-row hairs. These (anterior) pattern elements are not accounted for in the blastoderm pattern. They may be derived as a consequence of the postblastoderm splitting of the broad engrailed stripes. 


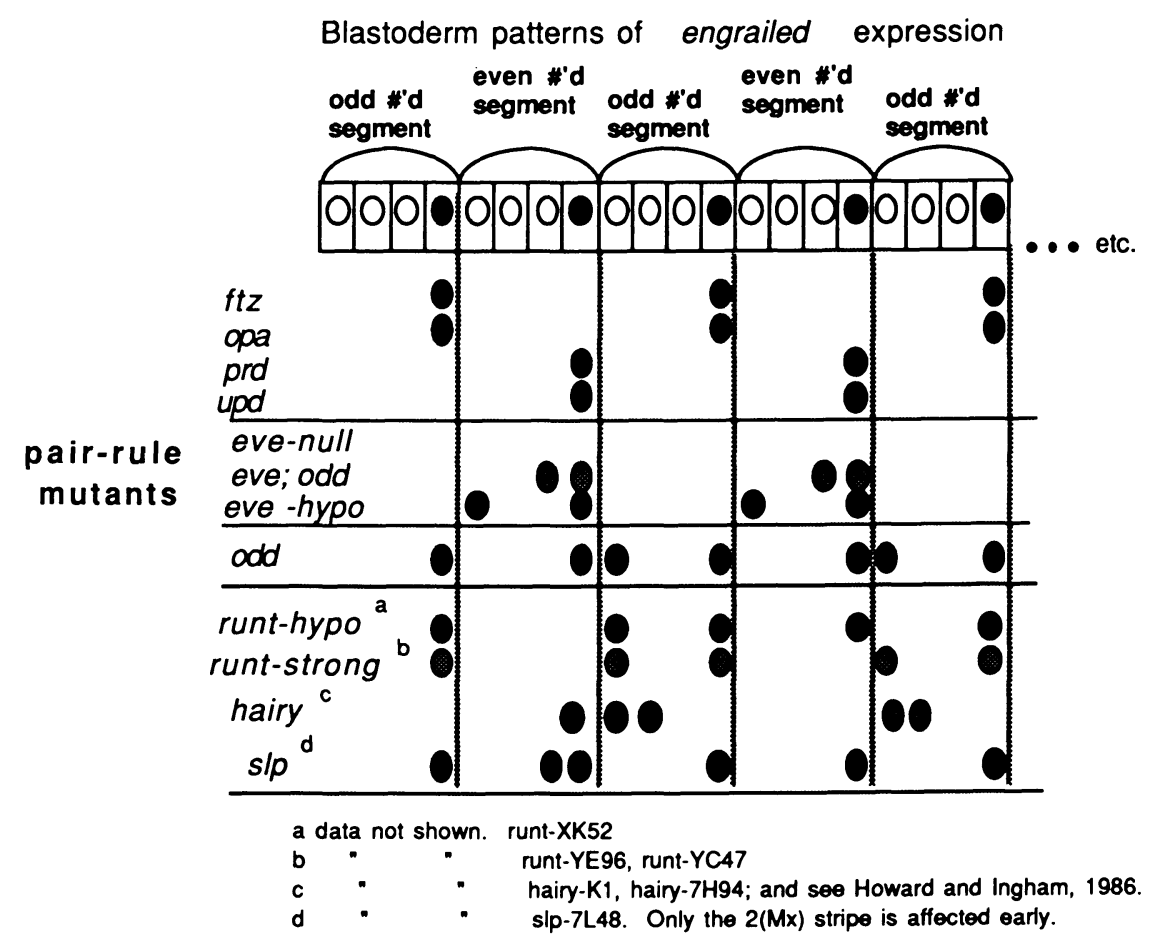

Figure 6. Summary of the changes in engrailed expression at cellular blastoderm in pair-rule mutant embryos. Roughly five segments worth of blastoderm cells (rectangular boxes containing oval nuclei) are shown, where every fourth cell expresses engrailed. This is the wild-type configuration. For convenience, a segment primordium is assigned four cells. Actual cell counts give an average of 3.4 cell diameters in ventrolateral regions (S. DiNardo, unpubl.). Odd-numbered segments alternate with even-numbered segments. The pair-rule mutants considered in this work are listed along the left-hand margin, roughly in the order considered in the Results. Registration lines are placed at the presumptive segment boundaries. The shaded ovals represent nuclei where engrailed expression is found in each of the mutants examined. Black ovals have been as precisely aligned as possible (not more than one cell diameter off). Thus, in odd mutants, the expansion in engrailed domain is into the posteriorly adjacent row of cells. Those nuclei shaded with hatching are only approximately positioned and could be off a few cell diameters. Because the runt hypomorphic and hairy mutants do not exhibit precisely periodic patterns, successive double segment intervals show alternative patterns. Strong runt alleles exhibit a more complicated engrailed pattern at some positions along the anteroposterior axis (S. DiNardo, unpubl.). Also, in early slp mutants, only one engrailed stripe is altered; the $2(\mathrm{Mx})$ stripe is broadened. Note that with the exception of $f t z$ and prd, the mutant patterns are altered dramatically by postblastoderm events, and these changes are not illustrated here.

en stripes are expanded to two cells, as if odd activity normally serves to repress en. In an eve mutant, the domain of odd expression or activity may be expanded and effectively repress the even-numbered en stripes.

Second, we are intrigued by those pair-rule mutations that cause a shift in position, rather than a deletion, of particular engrailed stripes (e.g., runt). The simplest explanation for such a shift is that the particular mutation causes alterations in the expression patterns of several of the other pair-rule genes as a consequence of the regulatory interactions among these genes. This suggests that a gene such as runt may only exert an effect on en indirectly, possibly through direct control of other pair-rule genes. This supports the notion that a functional subdivision(s) exists within the pair-rule gene class (Carroll and Scott 1986; Howard and Ingham 1986).

\section{Elaborating upon the blastoderm framework of pattern as development continues}

We have cataloged the stereotyped alterations in en blastoderm pattern due to pair-rule mutations (Fig. 6). However, in most mutants we find that the en pattern changes, often dramatically, after the germ band is fully extended, and that these late changes have consequences for the final body pattern. Therefore, an understanding of pattern formation not only requires a determination of the processes that establish spatially patterned gene expression at blastoderm but also an identification of the processes that cause the later changes that are superimposed on the early pattern. Because these changes occur after the major time period of pair-rule activity (in epidermal precursors), it is likely that these late changes are a consequence of the earlier pattern defects. The changes could result from cell death or cell rearrangements at the later embryonic stages. To some extent, both of these probably contribute to the final patterns we observe. In addition, some of the changes may be due to changes in the state of gene expression, reflecting a respecification of cell fate.

Two features of the development of odd mutants suggest that pattern regulation (French et al. 1976; Wright and Lawrence 1981) is responsible for the temporal alteration of engrailed signal described in odd mutants. First, the production of non-engrailed-staining cells with anterior fates in the middle of an engrailed-expressing region 
is consistent with the production of new cell identities during regulation. Second, the production of a mirrorimage duplication is characteristic of many patterns produced during a regulative response. Clearly, the process of pattern regulation suggests the involvement of cell communication during this period of development.

The extent of the pattern adjustment accomplished by this regulative response is variable, perhaps because the decision to respecify is probabilistic when the starting
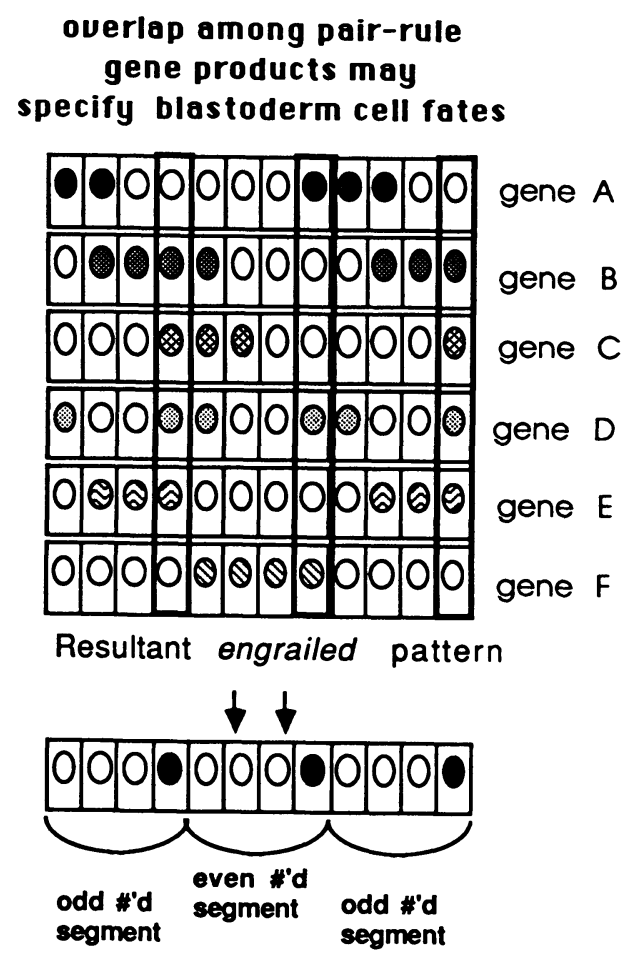

Figure 7. A scheme depicting one model for the combinatorial code of pair-rule gene products at cellular blastoderm and the resultant engrailed pattern. The pattern of expression of each gene, $A-F$, is shown for 12 cells /corresponding to three segment primordia) at an arbitrary position along the A-P axis of the embryo. The patterns for genes $E$ and $F$ are hypothetical but that for $A-D$ are compiled from the literature. The accumulated products are shown as nuclear proteins for convenience. Gene $A$ represents $f t z$; the overlap between $f t z$ and engrailed (nuclear) protein stripes has been directly determined (S. DiNardo and S.B. Carroll, unpubl.). (Gene $B$ ) hairy (Ingham et al. 1985); (gene C) eve (Harding et al. 1986; MacDonald et al. 1986); (gene D) prd (Kilcherr et al. 1986). Note that each pairrule gene is expressed in relatively broad stripes, which overlap to varying extents. As a result, any vertical row of blastoderm cells has a unique combination of pair-rule products. Combinations that allow engrailed induction in this scheme are highlighted. Note that the particular combinations alternate for odd- and even-numbered stripes. It is likely that some other segment polarity genes would respond to other combinations and, therefore, come to be expressed in single-cell-wide stripes, marking other cells within a segment primordium. We emphasize that this is a static picture of a very dynamic process, where the expression patterns are developing and decaying quickly. The precise kinetics of accumulation and decay may be of paramount importance (see MacDonald et al. 1986). pattern is highly abnormal and the developmental time during which adjustments can be made is short. In their analysis of runt, Gergen and Weischaus (1985) have also suggested that cell-cell interactions may be responsible for intercalating new cell identity at the borders of pattern defects.

In summary, by the cellular blastoderm stage, one accomplishment of the interactive set of regulatory products produced by the pair-rule genes is the establishment of the precise metameric nature of the embryo. This is elegantly manifested by the single-cell-wide stripes of expression of engrailed. Moreover, at least some of these same pair-rule gene products are involved in the establishment of the identity of these segment primordia, by virtue of their proposed control over homeotic gene expression (Duncan 1986; Ingham and Martinez-Arias 1986). The further elaboration of pattern within the segmental primordia relies on a (continued) gene regulatory hierarchy, involving engrailed, homeotic genes (Struhl 1982), and segment polarity genes, some of which may play a role in cell-cell interactions (Rijsewijk et al. 1987).

\section{Materials and methods}

\section{Culture conditions}

Flies were kept as balanced stocks and reared at $25^{\circ} \mathrm{C}$.

\section{Genotypes used}

Pair-rule mutants were generously provided by the laboratories of C. Nüsslein-Volhard and E. Wieschaus. The strongest alleles available were used (genetic nulls or molecular nulls, if known), unless indicated. The specific alleles are designated in the appropriate figure legend. Similar staining patterns have been observed using different alleles for $f t z\left(f t z^{W 20}\right.$ and $\left.f t z^{E 66-1}\right)$, opa (opa ${ }^{I I C 42}$ and opa $\left.a^{I I 32}\right)$, and $h\left(h^{K 1}\right.$ and $\left.h^{7 H 94}\right)$. With the exception of stocks or crosses involving the FM7 balancer chromosome, we find no complications due to the specific balancer chromosome used (most often $\mathrm{CyO}$ and TM3, Sb, or Ser). The segregation of the FM7 chromosome gives rise to defective blastoderm embryos at a frequency of about $5 \%$, as determined by outcrosses. Therefore, this minor class of embryos, which die shortly after gastrulation, has been taken into account in our analysis of runt and upd. We have also checked the engrailed patterns in runt mutant embryos derived from crosses in which no balancer chromosomes were segregating. Mutant patterns observed in (hemi- or homozygous) runt ${ }^{Y E 96}$, runt ${ }^{\text {YC43, }}$ and heteroallelic runt ${ }^{Y C 43} /$ runt $^{Y E 96}$ embryos are similar.

\section{Cuticle preparations}

In most cases, collections from the same parents as those used for analysis of engrailed patterns were aged until all viable animals had hatched. Mutant embryos were then mounted and cleared for cuticular analysis (Van der Meer 1977; Gergen and Weischaus 1985).

\section{Immunocytochemistry}

Fixation and indirect immunofluorescent staining was performed as in DiNardo et al. (1985) with minor modifications. Detailed protocols are available upon request. Primary anti- 
bodies used were the previously described affinity-purified rabbit polyclonal sera directed against the engrailed protein and monoclonal antibody FP.3.38 directed against Ubx, a kind gift of R. White and M. Wilcox (1984). Secondary antibodies in more recent work are biotinylated (Vector Labs) and used in conjunction with streptavidin horseradish peroxidase (BRL). In this case, the cytological stain is developed with diaminobenzidine and hydrogen peroxide (Sigma) according to protocols from manufacturers. Embryos are dehydrated, cleared in xylene or methylsalicylate, and mounted for viewing with Nomarski optics.

\section{Identity of engrailed stripes}

The segmental identity of a particular engrailed stripe in the mutants is determined by its correlation in position relative to morphological markers in wild type. In addition, these have been verified (especially in the complex cases, such as runt) by double labeling with anti-Ubx, because the pair-rule mutations generally do not alter segmental identity. Mutant embryos are identified by characteristic and reproducible changes in the pattern of engrailed expression. The fraction of such embryos approximated $25 \%$, except where noted in the text. For each mutant, roughly 10-50 mutant embryos at each developmental stage have been examined.

\section{Acknowledgments}

We are indebted to the geneticists who kindly provided mutant stocks and a free flow of unpublished information, especially the laboratories of E. Wieschaus, C. Nüsslein-Volhard, 'and M. Scott. We thank members of the lab for comments on the innumerable versions of this manuscript; Doug Coulter, Eric Wieschaus, Paul Sternberg, and Bruce Edgar for discussions and suggestions along the way; the Albert's Lab for generous use of their microscopes; and Judy Piccini for careful preparation of the manuscript. Lastly, we honor two of our rabbits. The work was supported by National Science Foundation grants GM 37193 and GM 31286 from the National Institutes of Health, and DCB 8418016 from the National Science Foundation to P.O'F. S.D. was initially a Fellow of the Helen Hay Whitney Foundation and is now a Lucille P. Markey Scholar and is supported by the Lucille P. Markey Charitable Trușt.

\section{References}

Cabrera, C., J. Botas, and A. Garcia-Bellido. 1985. Distribution of Ultrabithorax proteins in mutants of Drosophila bithorax complex and its transregulatory genes. Nature 318: 569571.

Carroll, S.B. and M.P. Scott. 1985. Localization of the fushi tarazu protein during Drosophila embryogenesis. Cell 43: $47-57$.

1986. Zygotically active genes that affect the spatial expression of the fushi tarazu segmentation gene during early Drosophila embryogenesis. Cell 45: 113-126.

Desplan, C., J. Theis, and P.H. O'Farrell. 1985. The Drosophila developmental gene, engrailed, encodes a sequence specific DNA binding activity. Nature 318: 630-635.

DiNardo, S., J.M. Kuner, J. Theis, and P.H. O'Farrell. 1985. Development of embryonic pattern in D. melanogaster as revealed by accumulation of the nuclear engrailed protein. Cell 43: 59-69.

Doe, C.Q. and C.S. Goodman. 1985. Early events in insect neurogenesis. II. The role of cell interactions and cell lineage in the determination of neuronal precursor cells. Dev. Biol. 111:206-219.

Duncan, I.M. 1986. Control of bithorax complex functions by the segmentation gene fushi tarazu of Drosophila melanogaster. Cell 47: 297-309.

Fiose, A., W.J. McGinnis, and W.J. Gehring. 1985. Isolation of a homoeo box-containing gene from the engrailed region of Drosophila and the spatial distribution of its transcripts. Nature 313: 284-289.

Frasch, M., T. Hoey, C. Rushlow, H. Doyle, and M. Levine. 1987. Characterization and localization of the even-skipped protein in Drosophila. EMBO J. (in press).

French, V., P.J. Bryant, and S. Bryant. 1976. Pattern regulation in epimorphic fields. Science 193: 969-981.

Frigario, G., M. Burri, D. Bopp, S. Baumgartner, and M. Noll. 1986. Structure of the segmentation gene paired and the Drosophila PRD gene set as part of a gene network. Cell 47: 735-746.

Garcia-Bellido, A. 1975. Genetic control of wing disc development in Drosophila. CIBA Found. Symp. 29: 161-182.

Gehring, W. 1967. Clonal analysis of determination dynamics in cultures of imaginal disks in Drosophila melanogaster. Dev. Biol. 16: 438-456.

Gergen, J.P. and E.F. Wieschaus. 1985. The localized requirements for a gene affecting segmentation in Drosophila: Analysis of larvae mosaic for runt. Dev. Biol. 109: 321-335.

1986a. Dosage requirements for runt in the segmentation of Drosophila embryos. Cell 45: 289-299.

- 1986b. Localized requirements for gene activity in segmentation of Drosophila embryos: Analysis of armadillo, fused, Giant, and unpaired mutations in genetic mosaics. Wilhelm Roux's Arch. Dev. Biol. 195: 49-62.

Gergen, J.P., D. Coulter, and E. Wieschaus. 1986. Segmental pattern and blastoderm identities. Symp. Soc. Dev. Biol. 43: 195-220.

Hafen, E., A. Kuroiwa, and W.G. Gehring. 1984. Spatial distribution of transcripts from the segmentation gene fushi tarazu during Drosophila embryonic development. Cell 37: 439-445.

Harding, K., C. Rushlow, H. Doyle, T. Hoey, and M. Levine. 1986. Cross-regulatory interactions among pair-rule genes in Drosophila. Science 233: 953-959.

Howard, K. and P. Ingham. 1986. Regulatory interactions between the segmentation genes fushi tarazu, hairy, and engrailed in the Drosophila blastoderm. Cell 44: 949-957.

Ingham, P.W. and A. Martinez-Arias. 1986. The correct activation of Antennapedia and bithorax complex genes requires the fushi tarazu gene. Nature 324: 592-597.

Ingham, P.W., K.R. Howard, and D. Ish-Horowicz. 1985. Transcription pattern of the Drosophila segmentation gene hairy. Nature 318: 439-445.

Jurgens, G., E. Wieschaus, C. Nüsslein-Volhard, and M. Kluding. 1984. Mutations affecting the pattern of the larval cuticle in Drosophila melanogaster. II. Zygotic loci on the third chromosome. Wilhelm Roux's Arch. Dev. Biol. 193: 283-295.

Karr, T.L., Z. Ali, B. Drees, and T. Kornberg. 1985. The engrailed locus of $D$. melanogaster provides an essential zygotic function in precellular embryos. Cell 43: 591-601.

Kilcherr, F., S. Baumgartner, D. Bopp, E. Frei, and M. Noll. 1986. Isolation of the paired gene of Drosophila and its spatial expression during early embryogenesis. Nature 321: 493-499.

Kornberg, T. 1981 a. engrailed: A gene controlling compartment and segment formation in Drosophila. Proc. Natl. Acad. Sci. 78: 1095-1099. 
1981b. Compartments in the abdomen of Drosophila and the role of the engrailed locus. Dev. Biol. 86: 363-372.

Kornberg, T., I. Siden, P. O'Farrell, and M. Simon. 1985. The engrailed locus of Drosophila: In situ localization of transcripts reveals compartment-specific expression. Cell 40: $45-53$.

Laughon, A. and M.P. Scott. 1984. Sequence of a Drosophila segmentation gene: Protein structure homology with DNA binding proteins. Nature 310: $25-31$.

Lawrence, P.A. and G. Morata. 1976. Compartments in the wing of Drosophila: A study of the engrailed gene. Dev. Biol. 50: 321-337.

MacDonald, P.M. and G. Struhl. 1986. A molecular gradient in early Drosophila embryos and its role in specifying the body pattern. Nature 324: 537-545.

MacDonald, P.M., P. Ingham, and G. Struhl. 1986. Isolation, structure, and expression of even-skipped: A second pairrule gene of Drosophila containing a homeobox. Cell 47: $721-734$.

Nüsslein-Volhard, C. and E. Wieschaus. 1980. Mutations affecting segment number and polarity in Drosophila. Nature 287: 795-801.

Nüsslein-Volhard, C., E. Wieschaus, and H. Kluding. 1984. Mutations affecting the pattern of the larval cuticle in Drosophila melanogaster. I. Zygotic loci on the second chromosome. Wilhelm Roux's Arch Dev. Biol. 193: 267-282.

Nüsslein-Volhard, C., H. Kluding, and G. Jurgens. 1985. Genes affecting the segmental subdivision of the Drosophila embryo. Cold Spring Harbor Symp. Quant. Biol. 50: 145-154.

Ready, D.F., T.E. Hanson, and S. Benzer. 1976. Development of the Drosophila retina, a neurocrystalline lattice. Dev. Biol. 53: 217-240.

Rijsewijk, F., M. Schuermann, E. Wagenaar, P. Parren, D. Weigel, and R. Nusse. 1987. The Drosophila homology of the mouse mammary oncogene int-1 is identical to the segment polarity gene wingless. Cell 50: 649-657.

Scott, M.P. and P.H. O'Farrell. 1986. Spatial programming of gene expression in early Drosophila embryogenesis. Annu. Rev. Cell Biol. 2: 49-80.

Simcox, A.A. and J.H. Sang. 1983. When does determination occur in Drosophila embryos? Dev. Biol. 97: 212-221.

Struhl, G. 1982. Genes controlling segmental specification in the Drosophila thorax. Proc. Natl. Acad. Sci. 79: 73807384.

- 1985. Near-reciprocal phenotypes caused by inactivating or indiscriminately expressing the Drosophila segmentation gene $f t z$. Nature 318: 677-680.

Szabad, J., T. Schupbach, and E. Wieschaus. 1979. Cell lineage and development in the larval epidermis of Drosophila melanogaster. Dev. Biol. 73: 256-271.

Van der Meer, S. 1977. Optical clean and permanent whole mount preparation for phase contrast microscopy of cuticular structures of insect larvae. Dros. Inf. Serv. 52: 160.

Wakimoto, B.T. and T.C. Kaufman. 1981. Analysis of larval segmentation in lethal genotypes associated with the $A n$ tennapedia gene complex in Drosophila melanogaster. Dev. Biol. 81: 51-64.

Weischaus, E. and W. Gehring. 1976. Clonal analysis of primordial disc cells in the early embryo of Drosophila melanogaster. Dev. Biol. 50: 249-263.

Weischaus, E., C. Nüsslein-Volhard, C. and G. Jurgens. 1984a. Mutations affecting the pattern of the larval cuticle in Drosophila melanogaster. III. Zygotic loci on the $X$-chromosome and fourth chromosome. Wilhelm Roux's Arch. Dev. Biol. 193: 296-307.

-1984b. Kruppel, a gene whose activity is required early in the zygotic genome for normal embryonic segmentation. Dev. Biol. 104: 172-186.

White, R.A.H. and M. Wilcox. 1984. Protein products of the Bithorax Complex in Drosophila. Cell 39: 163-171.

Wright, D.A. and P.A. Lawrence. 1981. Regeneration of the segment boundary in Oncopeltus. Dev. Biol. 85: 317-327. 


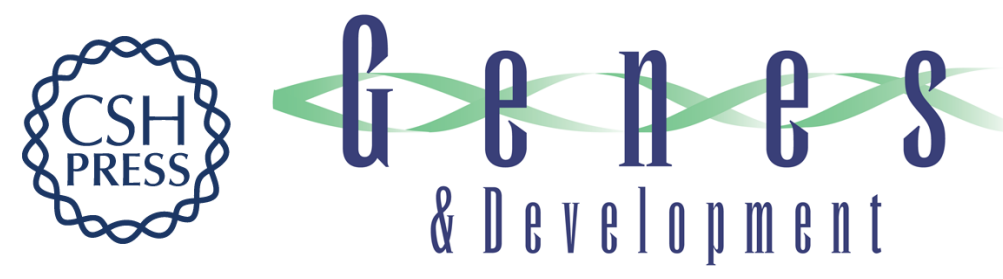

\section{Establishment and refinement of segmental pattern in the Drosophila embryo: spatial control of engrailed expression by pair-rule genes.}

S DiNardo and P H O'Farrell

Genes Dev. 1987, 1:

Access the most recent version at doi:10.1101/gad.1.10.1212

References This article cites 48 articles, 4 of which can be accessed free at:

http://genesdev.cshlp.org/content/1/10/1212.full.html\#ref-list-1

License

Email Alerting Receive free email alerts when new articles cite this article - sign up in the box at the top Service right corner of the article or click here.

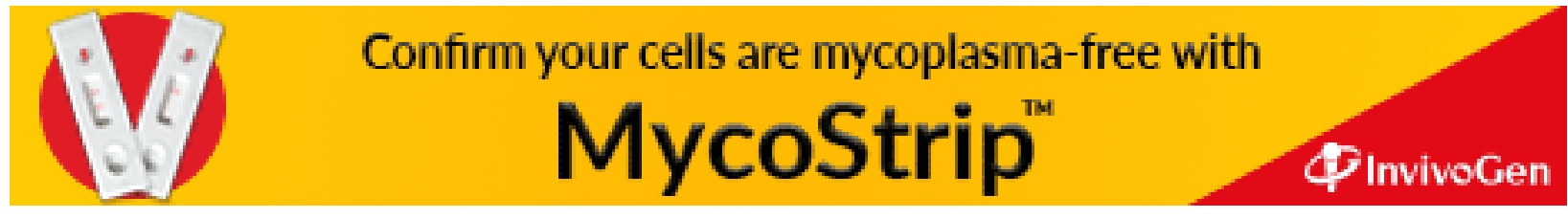

